\title{
PLATO AND THE DANGEROUS PLEASURES OF POIKILIA*
}

\begin{abstract}
A significant strand of the ethical psychology, aesthetics and politics of Plato's Republic revolves around the concept of poikilia, 'fascinating variety'. Plato uses the concept to caution against harmful appetitive pleasures purveyed by democracy and such artistic or cultural practices as mimetic poetry. His aim, this article shows, is to contest a prominent conceptual connection between poikilia and beauty (kallos, to kalon). Exploiting tensions in the archaic and classical Greek concept, Plato associates poikilia with dangerous pleasures to redirect admiration toward a distinctly philosophical pursuit of the nature of beauty. This is to displace a prominent and problematic cultural sensibility - the aesthetics of poikilia - not to deny that fascinating variety, even in mimetic poetry, may be beautiful. Rather, Plato's cultural critique lays bare an epistemological problem in the ethical psychology of beauty: since they cannot be distinguished from what seems beautiful, how should one respond to fascinating yet dangerous attractions?
\end{abstract}

Keywords: Plato; pleasure; beauty; poikilia; kalon; ethical psychology; ancient Greek aesthetics; lovers of sights and sounds

Central to the ethical psychology, aesthetics and politics of Plato's Republic is the concept of poikilia. Denoting the fascinating experience of various colours, sounds or textures, as well as of intellectual cunning, the concept of poikilia embodies a tension in archaic and classical Greek thought that beauty (to kalon, kallos), though central to living well, can captivate the senses and mind in disastrous ways. ${ }^{1}$ It is against this cultural background that Plato uses the concept to caution against attractive but harmful pleasures purveyed by democracy (Resp. 557c5, 558c1-2, 559d7-8, 561e3-8), musical and other cultural practices (398d7-399e12, 404d1-e6) and mimetic poetry (604e1-605a6). Because the concept connects ethically deficient psychological, political and artistic structures, Plato might seem to judge poikilia unequivocally harmful and not beautiful. ${ }^{2}$ However, the concept occupies a more complicated role in the dialogue, one with significant implications for Plato's ethical psychology and aesthetics.

* I would like to extend sincere thanks to Wolfgang Mann, Lydia Goehr, Pauline LeVen, Nickolas Pappas, Elizabeth Scharffenberger and an anonymous referee for $C Q$ for their valuable comments on earlier drafts of this paper, and to Laura Martin for reminders of its contemporary importance.

${ }^{1}$ Though it is uncontroversial to treat kallos as analogous to the concept of beauty, it remains standard to construe to kalon as primarily the fine, admirable or noble and only derivatively the beautiful for lexical reasons discussed by P. Woodruff, Plato Hippias Major (Oxford, 1982) and D. Konstan, Beauty: The Fortunes of an Ancient Greek Idea (New York, 2014). Yet beauty is, like the kalon, an aesthetic and an ethical concept. More specifically, Plato's treatment of poikilia is unintelligible without emphasis on the aesthetic dimensions of the kalon in ethical motivation and evaluation.

2 A widespread view: J. Moss, 'What is imitative poetry and why is it bad?', in G.R.F. Ferrari (ed.), The Cambridge Companion to Plato's Republic (Cambridge, 2007), 415-44, at 426, 435-7; Z. Petraki, The Poetics of Philosophical Language: Plato, Poets and Presocratics in the Republic (Berlin, 2011), 64-5, 181-5, 235-50; R.S. Liebert, 'Apian imagery and the critique of poetic sweetness in Plato's Republic', TAPhA 140 (2010), 97-115 and ead., Tragic Pleasure from Homer to Plato 
A re-examination is necessary because the dialogue grants positive heuristic value to

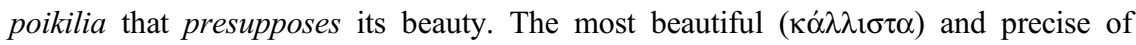
visible phenomena, the astronomical bodies and their observable motions_poikilmata and poikilia in Socrates' phrase (529b1, 529d8) — can and should be studied as models of intelligible astronomical patterns. Indeed, by admiring their complexity, one may come to understand the cosmos as the most beautiful work of a divine, benevolent intel-

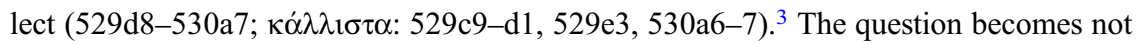
just how this use of poikilia coheres with its abuse throughout the dialogue but, more fundamentally, what Plato is doing with and to this concept in the Republic. In particular, how does poikilia relate to beauty?

This article shows that Plato contests a prominent cultural sensibility-the aesthetics of poikilia - which presumes a conceptual connection between poikilia and beauty. Plato exploits tensions in the former concept to sever this connection, because, in his view, this connection promotes an indiscriminate pursuit of pleasure and precludes a distinctly 'philosophical' engagement with beauty. Yet, far from denying that poikilia may be beautiful, his treatment lays bare a problem in the pursuit of beauty: one must learn to negotiate fascinating yet dangerous attractions, for such attractions cannot be distinguished from the experience of beauty.

At stake in this interpretation is not simply a richer understanding of the substance and detail of a significant if neglected argument of the dialogue. It has broader historical and philosophical ramifications. Because the concept of poikilia marks a privileged mode of sense-perception, its genealogy holds for scholars of ancient aesthetics potential insight into how certain ancient Greeks perceived their world. Our current historical narrative, however, takes Plato's criticisms to show that archaic delight in variety gave way to a radically different classical sensibility. To re-examine those criticisms is to re-examine this narrative. Philosophically, by appreciating that Plato grants that poikilia may be beautiful, we may cast fresh light onto the decisive role he accords beauty in learning to live well.

My argument proceeds in three stages. Section I outlines the historical sensibility that presumes a conceptual connection between poikilia and beauty. The following two sections reconstruct how and why Plato contests this sensibility. I show in section II how the attempt to dissociate poikilia from beauty underlies the seemingly disparate charges of immoderate pleasure in the soul, politics and arts, while section III examines

(Cambridge, 2017), 134-55; also B. Rosenstock, 'Athena's cloak: Plato's critique of the democratic city in the Republic', Political Theory 22 (1994), 363-90; S. Halliwell, The Aesthetics of Mimesis: Ancient Texts and Modern Problems (Princeton, 2002), 93-4, 325; R.W. Wallace, 'Plato, poikilia, and New Music in Athens', in E. Berardi, F. Lisi and D. Micalella (edd.), Poikilia. Variazioni sul tema (Acireale, 2009), 201-13; J.I. Porter, The Origins of Aesthetic Thought in Ancient Greece: Matter, Sensation, and Experience (Cambridge, 2010), 86-7; A. Grand-Clément, 'Poikilia', in P. Destrée and P. Murray (edd.), A Companion to Ancient Aesthetics (Malden, MA and Oxford, 2015), 406-21, at 415-16, though recognizing the need for reappraisal at ead., La fabrique des couleurs: histoire du paysage sensible des Grecs anciens (Paris, 2011), 488 n. 436.

${ }^{3}$ Cf. Ti. 39d2-40a9, Phd. 110b5-d7, on which see A. Nightingale, 'The aesthetics of vision in Plato's Phaedo and Timaeus', in A. Kampakoglou and A. Novokhatko (edd.), Gaze, Vision, and Visuality in Ancient Greek Literature (Berlin, 2018), 331-53. Leg. 665c2-6, Menex. 234c4-235c4, Phdr. 277b5-c6 attest the pedagogical value of poikilos speech and song, on which see M. Tulli, 'Una Spaltung: Platone, la poikilia e il sapere', in E. Berardi, F. Lisi and D. Micalella (edd.), Poikilia: variazioni sul tema (Acireale, 2009), 227-38. Prior to questions of development across dialogues is the question of how Socrates can, and why he does, admit the beauty of poikilia within the dialogue that criticizes it most severely. 
the metaphysical and epistemological dimensions of this critique, an attempt to redirect admiration toward the non-sensible nature of beauty. Both stages reveal a profound ambivalence toward poikilia, whether in Socrates' attraction to mimetic poetry or in wonder at the starry heavens, to suggest that Plato recognizes the risk that attractions to beauty may subvert a good life.

\section{THE AESTHETICS OF POIKILIA}

It is necessary first to review the conceptual history of poikilia. For it is seldom remarked, particularly in the philosophical literature, that Plato is concerned with historically specific, descriptively thick and affectively charged meanings of poikilia rather than with such thin notions as variety or multiplicity simpliciter. It will suffice to focus on patterns of conceptual use that Plato appropriates or subverts, most pressingly the tendency in archaic and classical discourse to presuppose that poikilia is necessary or sufficient for beauty. This tendency regulates an aesthetic and ethical sensibility that I shall call the aesthetics of poikilia.

In archaic poetry, the adjective poikilos praises primarily the fascinating effect of juxtaposing various colours, patterns, fabrics, sounds or other elements. The verb poikillo refers to the skilful activity of a craftsperson that produces this effect. The adjective also praises the mental agility of animals, heroes or divinities endowed with cunning intelligence (mêtis). ${ }^{4}$ While the prominence of these terms suggests that archaic poets and audiences relish 'the variegated nature of the objects of their senses' ${ }^{5}$ the concept refers not merely to a property of an object but essentially to a fascinated experience of a perceiver.

This experience is often explicitly marked as the experience of beauty. Recall Anchises wondering at Aphrodite clad as a maiden in a pampoikilos robe:

Now when Anchises saw her, he marked well and wondered ( $\theta \alpha v \dot{\mu} \alpha \mathbf{v \varepsilon v})$ at her appearance and height and shining garments. For she was wearing a dress more radiant than the brightness of

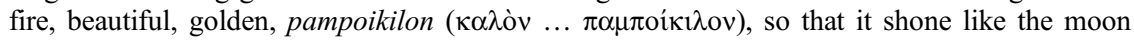
over her tender breasts, a wonder to behold $(\theta \alpha \hat{\nu} \mu \alpha$ i $\delta \varepsilon \dot{\varepsilon} \sigma \theta \alpha \imath){ }^{6}$

Connected to the seductive radiance and lush texture of beauty, what is (pam)poikilos bespeaks divinity; rightly suspecting her a god, Anchises fears the maiden but is overcome by erotic desire (Hymn. Hom. Ven. 5.93-106, 185-91). Similarly, when Hecuba wishes to entreat Athena, she selects from among her pampoikila robes 'one that was

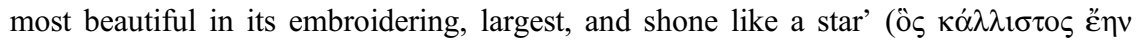

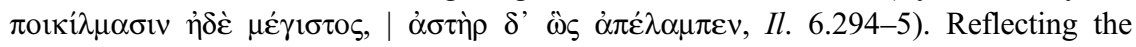
privileged status of poikilia in archaic gift exchange, these robes, all beautiful, are treasured: gifts for the queen, kept in a vault, befitting the divine. ${ }^{7}$

The essential point, however, is this: whether of persons or artefacts, the fascinating experience of poikilia is fundamentally ambivalent even—or especially-when praised as the experience of beauty. Odysseus' description of his marvellous brooch provides an

\footnotetext{
${ }^{4}$ Grand-Clément (n. 2 [2011]), 418-88 provides a comprehensive lexical survey.

5 So B.H. Fowler, 'The archaic aesthetic', AJPh 105 (1984), 119-49, at 119.

${ }^{6}$ Hymn. Hom. Ven. 5.84-90. Translations throughout are my own, based on the text of standard editions.

${ }^{7}$ Gift exchange: e.g. Od. 15.104-8, 125-7, 205-7; 18.292-6 (collocated with $\pi \varepsilon \rho ı \kappa \alpha \lambda \lambda \dot{\varepsilon} \alpha$ ); Sappho, fr. 44.8-10 Voigt.
} 
exemplary case in point, which reveals several aspects of the concept from which this ambivalence derives (Od. 19.227-31):

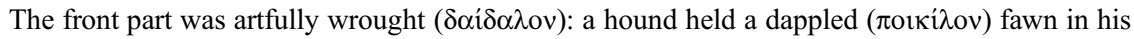
forepaws, preying on it as it struggled; and all marvelled ( $\theta \alpha \nu \mu \alpha \dot{\zeta} \zeta \varepsilon \sigma \kappa o v)$ how, though they were

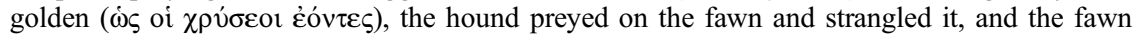
struggled with its feet as it tried to escape.

The Homeric poet locates wonder and, by implication, beauty in fascinating optic effects, marked by poikilos and its semantic cousin, daidalos, which emphasizes elaborate craftsmanship. The former refers first to the dappled aspect of the golden fawn, a common application of the term to an animal's spotted, iridescent or complexly patterned exterior. But it refers also to the apparent motion of the fawn and the hound. ${ }^{8}$ Together these referents structure perception around the sensuous surface of the brooch. So it is that viewers perceive the animals in the elaborated, shimmering gold, marvelling at how inanimate metal seems to come alive. ${ }^{9}$

And yet the scene is a violent struggle of life and death, a metonym for the danger of poikilia. The hound captures the fawn like the brooch captivates its viewers, and Odysseus his audience. These comparisons are encouraged by the nested frames through which the poet assimilates the imagination of Odysseus' audience to the gazes of the awestruck viewers and to the paralyzed fawn meeting the ferocious gaze (as one could render $\lambda \dot{\alpha} \omega)$ of the hound. ${ }^{10}$ The fawn fears the hound; the poikilia of the brooch inspires fear, as an element of wonder (thauma); auditors, we shall see, are and should be suspicious of Odysseus. For although poikilos refers above to a fawn, it almost exclusively describes dangerous animals, particularly snakes, whose multicoloured, iridescent or complexly patterned skin camouflages, seduces prey or stuns predators. ${ }^{11}$ That is, their beauty is focally related to the exercise of cunning intelligence (mêtis), an ability, linked to virtue (aretē) and wisdom or skill (sophia), to adapt to circumstances and outwit others through deceit and disguise. ${ }^{12}$ In this connection, too, what is poikilos designates a beautiful and thus admirable, kalon, character. Hence Aesop's fable of the fox and the leopard (Aesop 12 Perry):

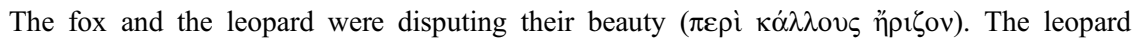

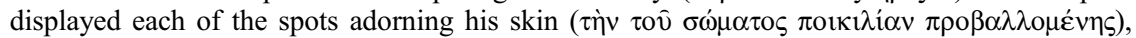
but the fox, interrupting him, said, "And how much more beautiful ( $\kappa \alpha \lambda \lambda i \omega v)$ than you am I,

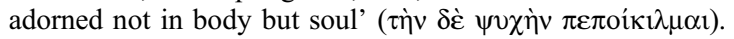

It is assumed that poikilia is sufficient, if not necessary, for beauty. The fox shows his beautiful wiles in manipulating the terms of the contest so that he comes out victorious. ${ }^{13}$ The worry is that such beauty also manipulates minds.

\footnotetext{
${ }^{8}$ Horse: Pind. Pyth. 2.8; leopard: Aesop 12 Perry; snake: Pind. Pyth. 4.249, 10.46, 8.46; Alcm. fr. 1.66 PMGF; Thgn. 1.602; bird: Pind. Pyth. 4.214-16; Alcm. fr. 345.2.

${ }^{9}$ Cf. R. Neer, The Emergence of the Classical Style in Greek Sculpture (Chicago, 2010), 59, 67, 113.

${ }^{10}$ For the alternate rendering, see Porter (n. 2), 447, following R. Prier, Thauma Idesthai: The Phenomenology of Sight and Appearance in Archaic Greek (Gainesville, FL, 1989), 32.

11 This is the sole use, to my knowledge, of poikilos for prey. It seems less an outlier than an inversion of typical associations of animal poikilia with predatory or defensive tactics.

${ }^{12}$ See M. Detienne and J.-P. Vernant (transl. J. Lloyd), Cunning Intelligence in Greek Culture and Society (Chicago, 1991), 18-44.

13 Thus it will fall to Socrates to show that an unjust person, secretly like Archilochus' crafty fox ( $\pi$ oเкí $\eta \nu$, Resp. 365c5-6), should not be admired and emulated, despite his reputation for justice.
} 
It is significant in this connection that Aphrodite lends Hera specifically a poikilos ribbon to seduce Zeus in the famous scene of deception at Il. 14.214-21:

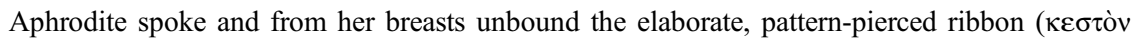

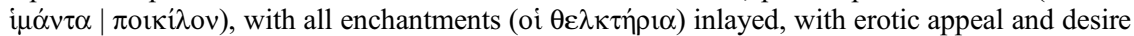
there ... 'Take this ribbon and hide it away in the fold of your bosom. It is elaborate ( $\pi$ oikí $\lambda$ ov), all things inlayed. And I think whatever is your heart's desire shall not go unaccomplished.'

Or we might consider how, at the climax of Aeschylus' Agamemnon, Clytemnestra entices the king to enter the palace via the richly embroidered purple tapestries on which, fit for the gods, Agamemnon hesitates to tread in case he should provoke divine envy: 'Being mortal, it is not for me or anyone to step on poikilois beauties

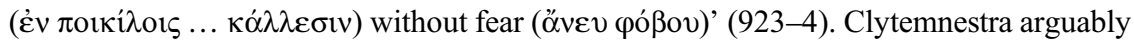
persuades him by exploiting his desire for envy among human beings, directing his attention to the wealth and power that the beautiful tapestries display. However opaque his psychology, though, the crucial significance of poikilia as a fascinating yet dangerous attraction is clear: Agamemnon repeats the term three times $(923,926,936)$ as he is led inside to be bound and murdered, not only metaphorically but now literally ensnared by Clytemnestra's woven plot. ${ }^{14}$

The ekphrasis of Odysseus' brooch obeys the same structure: a poikilos mind cunningly uses a poikilos artefact. None other than Odysseus, often called poikilométis for his wiles, ${ }^{15}$ describes the brooch in an artful speech that foregrounds issues of truthtelling and deception. Disguised as a beggar, Odysseus attempts to convince Penelope that he (the beggar) entertained Odysseus. Only moments earlier are we reminded that Odysseus makes many falsehoods seem true (Od. 19.203). This is high praise in the agonistic context of archaic poetry-how better to display skill at persuasion than by convincing someone of something false?-yet still such cleverness garners criticism. ${ }^{16}$ Penelope is suspicious; she tests the beggar by asking what Odysseus was wearing. The ekphrasis convinces her. Plato, we shall see, will buttress the suggestion that audiences guard against the power of poikilia by a psychological, political and metaphysical picture of a good human life.

The ground was well prepared. Ambivalence in archaic sources intensifies as the term poikilos becomes more pejorative with the rise of democracy at classical Athens. It comes to signify, on the one hand, the opposite of frank speech and transparency and, on the other hand, a barbarian or effeminate character. These latter connotations are due to the fact that members of the aristocracy appropriated from Persia and Eastern Greece a luxurious lifestyle, characterized by expensive clothing, perfumes and golden jewellery, to display their superiority once nouveaux riches began to compete in wealth. Through what Leslie Kurke has called the 'politics of habrosyne', aristocrats relied on

Tellingly, this first use of poikilos in the Republic comes in Adeimantus' challenge to Socrates to defend justice for its own sake against the poetic tradition.

${ }^{14}$ M. Mueller, Objects as Actors: Props and the Poetics of Performance in Greek Tragedy (Chicago, 2016), 55-6 shows that poikilia here relates the beauty and status of the tapestries to Clytemnestra's clever verbal tactics. For poikilia as feminized erotic charm, cf. Pind. Pyth. 4.21216; Eur. Med. 1159; Sappho, fr. 1.1-2 Voigt.

${ }_{15}$ Il. 11.482; Od. 3.163, 13.293; Eur. IA 526.

16 See further N. Worman, The Cast of Character: Style in Greek Literature (Austin, 2002), 108-92. Pindar similarly praises his odes as poikiloi (Ol. 3.8-9, 4.2-3, 6.87; Pyth. 9.77; Nem. 4.14, 5.41-2), yet

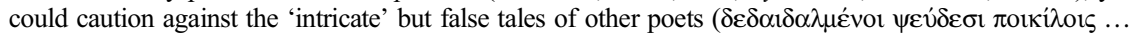
$\mu \bar{v} \theta 01$, Ol. 1.29). 
the beauty and social capital of poikilia to reclaim ethical and political status. ${ }^{17}$ Those sympathetic to the democracy could then invoke the term to stigmatize political enemies at home and, after the Persian War, abroad. By another turn, anti-democratic critics of the so-called New Music, to which we shall return, invoke poikilia as a metaphor for socio-political disorder.

These lexical changes have been taken to show that the concept of poikilia no longer tracks the fascinated experience of variegated materials, much less perceptions of beauty. ${ }^{18}$ Yet, rather than infer that the aesthetics of poikilia becomes defunct at classical Athens, in which case Plato could have no cause to dislodge this sensibility, it is more judicious to infer that the concept becomes more contested in the following two ways: (1) it becomes disputable whether what is poikilos is beautiful or otherwise praiseworthy; and (2) the concept comes to function as a label with which to claim artistic or socio-political status for oneself or to deny such claims of others. ${ }^{19}$ Such contestation is intelligible, though, only against a conceptual background in which poikilia remains tied to beauty, virtue and wisdom.

\section{CULTURAL CRITIQUE}

We may now examine how and why Plato exploits these conceptual tensions to displace the aesthetics of poikilia. I shall examine how in some detail but might anticipate broadly why: its spurious conception of beauty promotes an indiscriminate pursuit of pleasure and precludes a corrective 'philosophical' pursuit of beauty. This criticism depends on an assumption that one becomes like what one admires as beautiful (kalon). The assumption strikes a structural correspondence between what one admires and one's psychological constitution. ${ }^{20}$ Before examining its metaphysical reaches in the next section, I shall reconstruct how this assumption animates an attempt throughout the Republic to dissociate poikilia conceptually from beauty by assimilating the former to harmful, indeed shameful and ugly, pleasures.

\section{II.1 Tastes of democracy and aristocracy}

The cultural critique is most concentrated at Republic Book 8. There Socrates diagnoses the appeal of democracy in terms of the aesthetics of poikilia (Resp. 557c4-9):

${ }^{17}$ L. Kurke, 'The politics of $\dot{\alpha} \beta$ poov́vn in archaic Greece', ClAnt 11 (1992), 91-120. Grand-Clément (n. 2 [2011]), 328-38, 480-8 traces the broader lexical changes.

${ }^{18}$ So Grand-Clément (n. 2 [2015]), 416; P. LeVen, 'The colours of sound: poikilia and its aesthetic contexts', GRMS 1 (2013), 229-42, at 241. While these and related lexical changes may reflect changes in thought and sensibility, Neer (n. 9) shows that the concept of poikilia continues to regulate production and reception of classical sculpture and, in his Style and Politics in Athenian Vase-Painting (Cambridge, 2002), Attic red-figure.

${ }^{19}$ Cf. e.g. $P M G$ 708.5-10: Pratinas' satyr-chorus elevates their 'swanlike song of variegated wing'

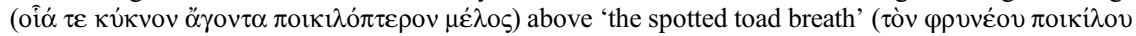
$\pi v o \alpha ́ v)$ of the aulos. This denies and at the same time appropriates the claim of aulos-players to artistic superiority, made under the banner of poikilia.

${ }^{20}$ A specific case of 'like encouraging like' (Resp. 425c1-2), this assumption lies behind the scheme of acculturation through beauty at Resp. Books 2-3 (401b1-402a6). Cf. 500c7-9 for its metaphysical expression, with section III below. 


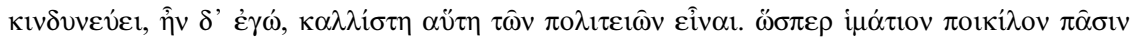

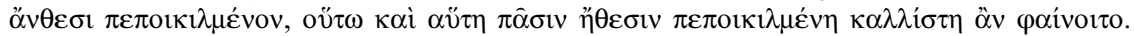

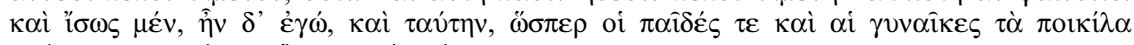

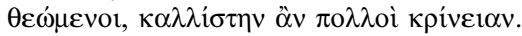

'Possibly,' I said, 'this is the most beautiful of the constitutions. Like an elaborate cloak embroidered in all colours, this city, embroidered with all kinds of character, would appear most beautiful. And perhaps,' I said, 'many people would judge it most beautiful, as women and children do when they see multicoloured things.'

Notice, first, that Socrates' collocations of 'most beautiful' with cognates of poikilia could have little sense were the conceptual connection between poikilia and the kalon no longer prominent. His remarks are constructed to undermine this connection. Socrates first hazards that democracy is ( $\left.\varepsilon^{\hat{i}} \alpha \alpha \mathrm{l}\right)$ the most beautiful regime, because it permits one to live howsoever one pleases (Resp. 557b8-10). He then qualifies that

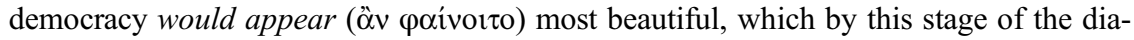
logue introduces quite some doubt, echoed by the shift from the indicative to the optative mood. Finally, Socrates weakens the claim still further, shifting the grammatical

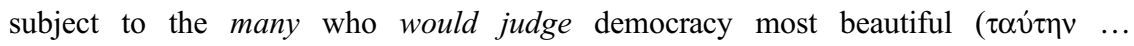

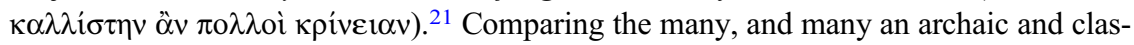
sical male, to a woman or a child suggests that they mistake fascinating variety of colours (patterns, pursuits and the like) for the nature of beauty.

It is, indeed, the nature of beauty at issue. The passage neither states nor implies that the diversity of democracy is not beautiful. It is often taken to do so, sometimes on the basis of a mistaken assumption that the term poikilos is entirely pejorative or itself connotes 'merely superficial beauty'. ${ }^{22}$ This force may be a consequence but cannot be the precedent of passages such as this. Notice that Socrates must labour to reveal an analogous mistake of the many concerning mimetic poetry. Seduced by its musical colours

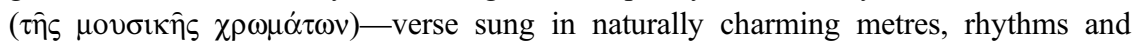
tunings $(\varphi v ́ \sigma \varepsilon 1 \ldots \kappa \dot{\lambda} \lambda \eta \sigma \mathrm{v})$ — they believe mimetic poets are experts in their subject matter (Resp. 601a5-b2). ${ }^{23}$ These charms, like the appeal of democracy, are relatively superficial, Socrates implies in a doubly erotic image: were its musical colours stripped off like clothing ( $\gamma \nu \mu \nu \omega \theta \dot{\varepsilon} v \tau \alpha, 601 \mathrm{~b} 2-3)$, mimetic poetry would look unattractive, akin to faces of once beautiful boys now bereft of the bloom of their youth ( $\tau$ ò öv $\theta 0 s, 601 b 7-9$ ). As we shall see, the fact that these charms cannot be extracted from mimetic poetry, particularly for someone under its fascinating spell, reflects a conceptual difficulty of disentangling beauty altogether from poikilia.

For the moment, however, our textual parallel shows that democracy seems beautiful to someone who looks uncritically, like the child who judges a tyrant beautiful from the outside without looking into his character (Resp. 577a3-7). ${ }^{24}$ Yet, while the child is

${ }^{21} \mathrm{Cf}$. N. Villacèque, 'De la bigarrure en politique (Platon, République, VIII, 557c4 sqq)', JHS 130 (2010), 137-52, at 143.

22 So Rosenstock (n. 2), 377; emphasis added. Compare Moss (n. 2), 426; Petraki (n. 2), 15 n. 28 , 242-3; Grand-Clément (n. 2 [2015]), 415-16. S. Monoson, Plato's Democratic Entanglements: Athenian Politics and the Practice of Philosophy (Princeton, 2000), 170-1 captures the evaluative nuance.

${ }^{23}$ This charm is soon characterized by poikilia (Resp. 604e-605a, on which see below), but skiagraphia is implicitly linked to poikilia by 365c3-6: like a crafty (poikilos) fox, the unjust person

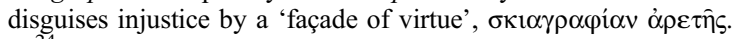

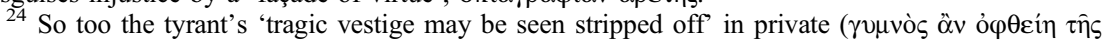

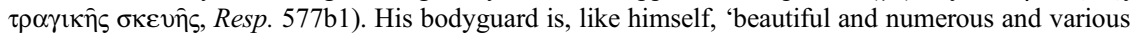


mistaken, the same cannot obviously be said of those who judge democracy and, to anticipate, mimetic poetry beautiful. ${ }^{25}$ The above passage implies only that it is incorrect to believe that being poikilos is identical to, necessary or sufficient for being beautiful. If

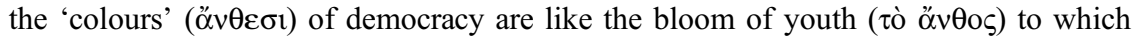
poetic poikilia is compared — as the wordplay suggests — then they should be beautiful, if fleetingly so. What matters is that the text leaves indeterminate the aesthetic status and the potential value of poikilia, a score on which we shall continue to find some ambivalence. Plato is unambivalent, however, about the need to displace its prominence as a criterion of beauty.

What is the harm? The tacit argument is that this misconception causes one to pursue pleasure indiscriminately and thus become, psychologically, as disunified as the objects one admires. To bring this argument into view, we might begin by noticing that the comparison of democracy to a multicoloured cloak does not simply convey the diversity of a theoretical model of democracy but diagnoses the aesthetics of poikilia as an animating principle of Athenian democracy. The simile refers to and attempts to neutralize two symbols, the Panathenaic peplos and the Stoa Poikile, with which democratic Athens glorified its identity, ideals and hegemony. Both symbols seem to have employed an artistic principle of poikilia to valorize poikilia as a principle of political composition. Socrates strikes a similarly deep accord between an emphasis in aesthetic judgement on sensory pleasure and the same emphasis in political life. In his estimation, democracy celebrates anarchy and license as freedom and equality, revaluing moderation and shame as illiberal because they inhibit the indiscriminate pursuit of pleasure (Resp. 557e1-558b9, 560d4-561c5). To conclude that democracy seems 'a pleasurable

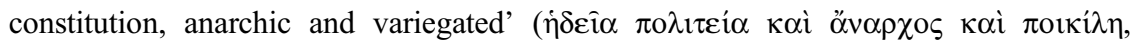
$558 \mathrm{c} 2-3$ ) is to propose that democracy is regulated by the connection first struck in archaic poetry between beauty and the sensory pleasures of poikilia and to undermine this connection by rendering such pleasures shameful.

This strategy turns against democracy the very rhetoric by which democrats derogated poikilia as an aristocratic appetite for sensual things. The strategy is necessary because, as Robert Seager, Josiah Ober and others remind us, democrats redefined existing political and ethical concepts, leading in many cases to 'the democratic pillaging of aristocratic values' ${ }^{26}$ Pressed to find a vocabulary to criticize democracy, Socrates uses its own anti-aristocratic valence to unmask its self-image.

Socrates elaborates the psycho-ethical harm of the aesthetics of poikilia through his analysis of the individual who typifies democracy, 'a multifarious man, full of all sorts

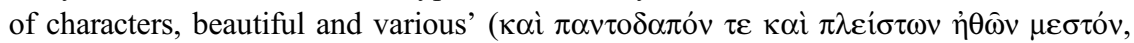

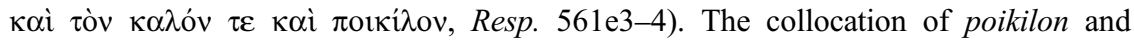

(poikilon) and never the same as itself' (568d6-7). Note here, too, the thick socio-political associations of poikilia: the guard consists of foreign mercenaries (567e1).

${ }^{25}$ The fascinating quality of poikilia has not been taken to complicate Socrates' attitude toward mimetic poetry, though it has been taken to complicate his attitude toward democracy. For Monoson (n. 22), Socrates admires democracy in so far as it provides philosophy a home and models of human psychology (at 166-9, 223-6). Her case, however, seems strained to compare $\pi \alpha \rho \alpha \delta \varepsilon i \gamma \mu \alpha \tau \alpha$ at Resp. $557 \mathrm{~d} 8$ with $529 \mathrm{~d} 8-9$. More promising is the observation of R. Blondell, The Play of Character in Plato's Dialogues (Cambridge, 2002), 67, 111, 142-61 that Socrates is characterized by a democratic ideal of versatility.

${ }^{26}$ So R. Seager in his 'Review of N. Loraux, L'invention d'Athenes: histoire de l'oraison funèbre dans la "cité classique" (Paris, 1981)', JHS 102 (1982), 267-8, at 268. J. Ober, The Athenian Revolution: Essays on Ancient Greek Democracy and Political Theory (Princeton, 1996), 155 applies the point to the present passage. 
kalon again evokes and calls into question their prominent conceptual connection. Precisely this connection underlies the envy and admiration of the many for this character,

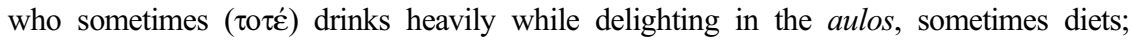
sometimes exercises, sometimes not; sometimes busies himself with what seems to him philosophy; but who often ( $\pi \mathrm{0} \lambda \lambda \dot{\alpha} \kappa \mathrm{k} \varsigma)$ leaps up in the assembly to speak and act as he pleases (561c7-d5). This is the glorious image of cunning Odysseus made political. ${ }^{27}$ To those reared on this ethical ideal, the motivational structure of the democratic individual seems beautiful, despite its lack of order and force of necessity. The criticism of democracy therefore extends to the underlying sensibility that supports and is supported by the regime.

The scope of the criticism must be emphasized to appreciate also that the image of the democratic individual criticizes the aristocracy for its delight in poikilia. Not only does the simile of the multicoloured cloak require the anti-aristocratic valence that democrats lend the term poikilos. Socrates' quip that if the democratic individual 'happens to admire soldiers, he's carried that way, if money-makers, that way' (кöv

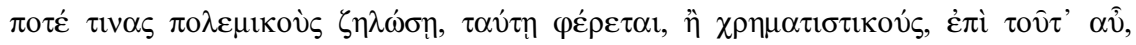
Resp. 561d5-7) seems deliberately to parody the aristocratic ideal of a poikilon èthos attested in the elegies attributed to Theognis (Thgn. $213-18 \approx 1071-4$ ): ${ }^{28}$

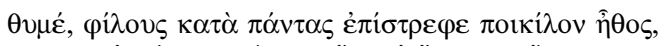

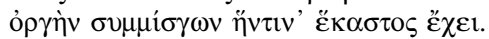

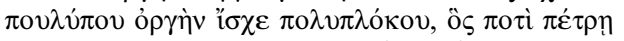

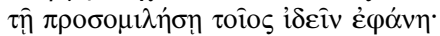

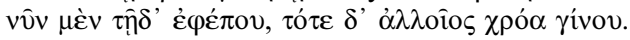

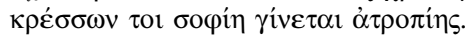

My heart, to all your friends keep turning your variable character, Mixing your temperament to the like of each.

Create the temperament of a tangled cuttlefish, which always makes itself look like whatever rock it has just clung to.

Now be like this; then, at another time, be like someone else in your colouring. Surely skill is better than inflexibility.

The advice is to cultivate an élite sociability, to mingle well with companions. Aristocrats would praise this variable character at symposia, that is, while attempting to consolidate power through ties of nobility in opposition to emerging democratic ideals. And they would perform this character, mingling sociably as they adopt fluid personalities by performing poetry as different personae, donning masks in the form of 'eye-cups' and, of course, getting drunk. ${ }^{29}$

Socrates contains the aristocratic ideal of the poikilon ethos in his criticism of the democratic individual - just as, please observe, the democratic individual contains first a symposiast drinking to the aulos - to yoke these factions together at the level of aesthetic-cum-ethical sensibility. Both democracy and aristocracy are structured by a conception of beauty as poikilia. This is a surprising and revisionary diagnosis, but it reinforces an earlier conceptual move. At Republic Book 3, Socrates and Glaucon

${ }^{27}$ Cf. Thuc. 2.41.1 with B.M.W. Knox, The Heroic Temper: Studies in Sophoclean Tragedy (Berkeley and Los Angeles, 1964), 121-2: 'the democratic viewpoint ... is Odyssean - an ideal of versatility, adaptability, diplomatic skill, and intellectual curiosity'.

${ }^{28}$ To my knowledge, this allusion has not yet been observed.

29 On political functions of poikilia on sympotic vases, see Neer (n. 9). 'Theognis' as persona of disaffected aristocrat: L. Kurke, 'Archaic Greek poetry', in H.A. Shapiro (ed.), The Cambridge Companion to Archaic Greece (Cambridge, 2007), 141-68, at 144-9. 
remove poikilia from the material culture of Kallipolis on the grounds that poikilia in

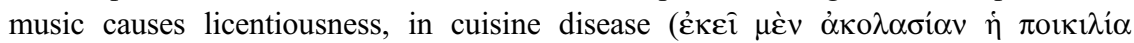

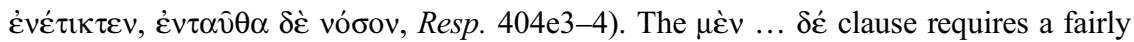
general sense of poikilia, perhaps captured by 'complexity' - one sufficiently flexible to connote the immoderate pursuit of appetitive pleasure in both musical and culinary practices. Yet it would be a mistake to infer that Socrates is thinning out the concept to fit his philosophical purposes. For he means to indict specific democratic and aristocratic practices for purveying a corrupt conception of beauty.

Democracy is indicted in the charge that, like panharmonic tunings played on multi-stringed instruments (Resp. 399c7-8), complex and various rhythmic feet

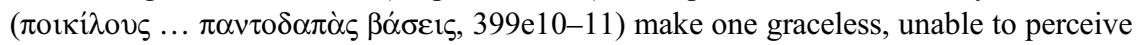
and cultivate the graceful beauty of a virtuous person. ${ }^{30}$ For poikilia is the staple of New Musicians, whose musical innovations-including increased instrumental range, mixed tunings and prioritizing the modulations of the aulos rather than fitting tuning and rhythm to verse (cf. 398d8, 400d4-5) — came to signify democratic revolution and inclusivity. While Socrates may have philosophical reasons to reject the view that music is beautiful to the extent that it excites psychosomatic upheaval, for rhetorical purposes he taps into the anxieties of his élite male interlocutors over the ecstatic power of the aulos to compromise their rational rule over themselves and others. ${ }^{31}$ His concern is that, because musical structures influence and are influenced by psychological and political structures (424c6-d4), to valorize musical poikilia is to reinforce a poor orientation to value in ethical and political life.

Less acknowledged than the democratic affiliation of musical poikilia is the aristocratic conception of beauty at stake in culinary poikilia. When Socrates recommends a simple

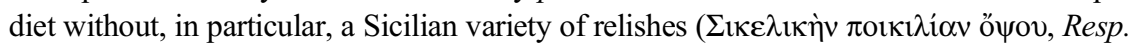
$404 \mathrm{~d} 2$ ), he is removing luxuries introduced by Glaucon's objection that one cannot live

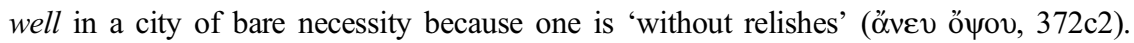
Glaucon's objection is not initially motivated by appetitive desires for pleasure, nor does he now set aside fancier tastes for the good of moderation or health. Rather, the exchange turns on the value of beauty, the kalon. Glaucon demands relishes owing to a spirited ambition to preserve his sense of a cultured and beautiful life, one worthy of admiration. ${ }^{32} \mathrm{He}$ wants to dine in the aristocratic manner to which he is accustomed

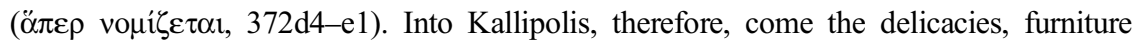

${ }^{30}$ Cf. Resp. 400d9-402a4, especially the primacy of beauty in tuning and rhythm (401d3-e1), discussed carefully by A.-E. Peponi, Frontiers of Pleasure: Models of Aesthetic Response in Archaic and Classical Greek Thought (Oxford, 2012), 144-53.

${ }^{31}$ See further E. Csapo, 'The politics of the New Music', in P. Murray and P. Wilson (edd.), Music and the Muses: The Culture of Mousike in the Classical Athenian City (Oxford, 2004), 207-48 with the observation of P. Leven, The Many-Headed Muse: Tradition and Innovation in Late Classical Greek Lyric Poetry (Cambridge, 2014), 101-3 that musicians politicized their music through the vocabulary of poikilia. Aulos as locus of anxieties: e.g. P. Wilson, 'The aulos in Athens', in S. Goldhill and R. Osborne (edd.), Performance Culture and Athenian Democracy (Cambridge, 1999), 58-95; R. Martin, 'The pipes are brawling: conceptualizing musical performance in Athens', in C. Dougherty and L. Kurke (edd.), The Cultures within Ancient Greek Culture: Contact, Conflict, Collaboration (Cambridge, 2003), 153-80.

${ }^{32}$ Here I am indebted to M.F. Burnyeat, 'Culture and society in Plato's Republic', The Tanner Lectures on Human Values 20 (1999), 215-324, at 230-6. P.W. Ludwig, 'Eros in the Republic', in G.R.F. Ferrari (ed.), The Cambridge Companion to Plato's Republic (Cambridge, 2007), 202-31 attends to spirit in this connection (at 225-6), though he takes the passage as evidence that spirited motivation should be eliminated. 
and accoutrements of the symposium, notably such conventional kala as painting, poikilia (presumably, embroidery), gold and ivory (373a1-9). ${ }^{33}$ How can Glaucon reject these attachments only moments later? It is at least in part because Socrates has in the meanwhile revalued poikilia as emasculate luxuries opposed to the masculine ideal of courage to which Glaucon is also attracted: 'real men' do not eat fish, much less Sicilian delicacies (404b5-c6). To regulate the culture by a standard of simplicity ( $\dot{\eta} \dot{\alpha} \pi \lambda \hat{\jmath}^{\prime} \tau \zeta$, , 404e4), then, is to displace a live standard of beauty at classical Athens by revaluing concrete forms of 'complexity' as ugly and shameful pleasures, not as emblems of an admirable life.

\section{2 Mimetic poetry reconsidered}

The criticism of poikilia in mimetic poetry at Republic Book 10 follows the same course. Because its historical context and its rhetorical subtext have not been appreciated, however, scholars have mistaken pejorative connotations of poikilia for a denial of its beauty. The concept, I argue, expresses Socrates' simultaneous repulsion and attraction toward mimetic poetry, tracing a far more ambivalent response than has traditionally been allowed. This ambivalence reflects a philosophical problem. One must negotiate how to respond to such fascinating yet dangerous attractions because these cannot be neatly separated from the experience of beauty.

The relevant charge is that by presenting 'the irascible and poikilos character' ( $\tau$ ò

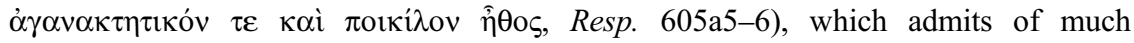

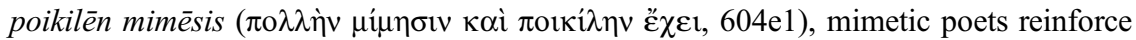
false values that undermine the rule of reason in the soul. The term 'irascible' ( $\dot{\alpha} \gamma \alpha v \alpha \kappa \tau \eta \tau$ $о$ óv) refers to the non-rational element that relishes in grieving the loss of someone dear (603e3-4) and impedes the ability of reason to measure suffering in light of a wider scheme of value (604c1-2). This element rules tragic heroes and the

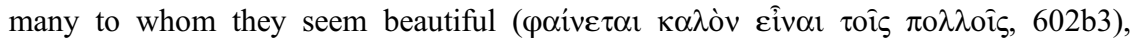
unsurprisingly, since virtuous conduct is alien to this motley crew ( $\pi \alpha v \eta \gamma u ́ \rho \varepsilon$ к $\alpha i$ $\pi \alpha \nu \tau o \delta \alpha \pi \circ \hat{\varsigma} \varsigma \dot{\alpha} v \theta \rho \omega \dot{\pi} \pi \mathrm{or} \varsigma, 604 \mathrm{e} 5$ ), reared as they have been to find poikilia paradigmatically beautiful. ${ }^{34}$ More opaque is what it means that this character admits of $\pi \mathrm{o} \lambda \lambda \dot{\eta} \nu \mu$ ú

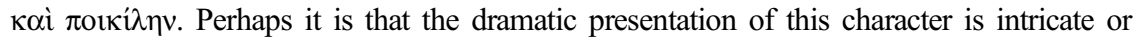
that it takes various forms because emotional turmoil can be expressed in various ways. ${ }^{35}$ Clearly, the phrase evokes connotations of sensory pleasure, psychological instability and deception that have accrued to the concept of poikilia, all of which caution against mimetic poetry. What, more specifically, do the terms of poikilia at Resp. 604e-605a imply?

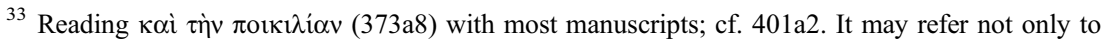
embroidery if counted among $\pi \dot{\alpha} \nu \tau \alpha \tau \dot{\alpha} \tau o 1 \alpha v \bar{\tau} \alpha$. For the aristocratic basis, cf. the lists of conventional kala at Hip. mai. 289d8-290b8, 298a1-5.

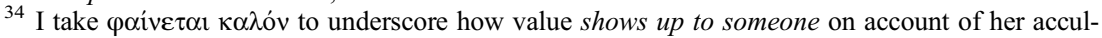
turation, reflecting the concern that mimetic poetry reinforces false values of the sort that Resp. Books 2-3 argues it instils. Here I cannot agree with Moss (n. 2), 424, for whom the force is ontological: 'value does not appear'. V. Harte, 'Republic 10 and the role of the audience in art', OSAPh 38 (2010), 69-96 notes how the audience contributes to the identification of mimetic poetry.

35 English translations reflect uncertainty whether poikilos is a quality of mimēsis (Grube, rev. Reeve: 'many multicolored imitations'), a quantity (Jowett: 'a great variety of materials for imitation'; Shorey: 'many and varied occasions for imitation') or both (Griffith: 'highly susceptible to all sorts of varied imitation'). 'Very intricate [complicated, etc.]' is possible, if unlikely, taking кoí intensively rather than copulatively.
} 
The tripartite division of the soul provides some clarification. For poikilia has become a term of art for appetitive desires, a 'diverse and many-headed beast'

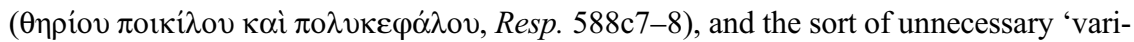

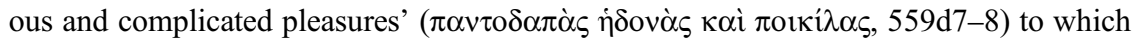
they are directed. To speak of 'the irascible and poikilos character' is to suggest, by referring jointly to the appetites and a debased form of spirit, the psychological diagnosis of the democratic individual who shamelessly pursues the immediate gratification of all pleasures. ${ }^{36}$ This psychological disintegration flows from a false evaluative and metaphysical picture, also suggested by the concept of poikilia, which, according to Socrates, motivates the excessive grief of tragic heroes. This is the picture sometimes proffered in tragedy that human life is beset by irreconcilable conflicts of value or by inexplicable suffering in an opaque cosmic order. However accurately this picture may register what Nietzsche called, echoing Resp. 602a-b and 604e-605a, the 'multicoloured and diverse' ('bunt und mannichfaltig') texture of our lives, Socrates exhorts one to believe that the order of being is knowable by reason and structured toward human happiness. ${ }^{37}$ Sympathy for tragic heroes perseveres a false worldview and precludes the philosophical commitments that might correct it.

Alongside these general resonances, however, we should remember that poikilon $\bar{e}$ thos refers in the context of tragedy less to a character 'stormy, passionate, emotional, full of inner conflict' than to the rather more specific cunning character of an Odysseus, Prometheus or Medea. ${ }^{38}$ This specific reference matters. It throws suspicion toward intellectual cunning at classical Athens onto actual models of democratic citizenship and the tragic poetry that glorifies those models. Such suspicion gains force from the connotation of poikilēn mimēsis of clever, tricky, or cunning craftsmanship, developing earlier comparisons of poets and painters to magicians who can create manifold appear-

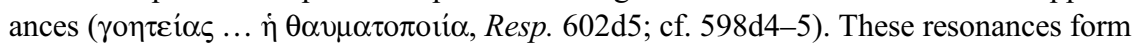
exactly the pattern of thought we found with Aphrodite, Clytemnestra and Odysseus: a poikilos mind (poet) uses a poikilos artefact (poetry) to manipulate senses and minds. Socrates unmasks this power by arguing that mimetic poets neither have nor need knowledge to gratify our silliest cognitive capacities. But his debt to this traditional pattern suggests more at work. After all, it leads to the remarkable claim that the mimetic

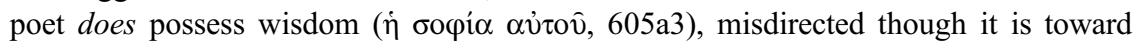
pleasing the crowd.

This concession of wisdom suggests that the concept of poikilia expresses a measure of admiration. While scholars standardly take Socrates to mean that mimetic poetry merely seems beautiful, en route to 'banishing' it without equivocation from the ideal constitution, we should take pause from the fact that the overall argument is far more provisional, reflecting what Stephen Halliwell has observed is an unresolved problem for Plato of reconciling a love of philosophy with a love of poetry. ${ }^{39}$ Socrates concedes

${ }^{36}$ Cf. Resp. 411b3-c3, with P. Destrée, 'Poetry, thumos, and pity in the Republic', in P. Destrée and F.-G. Herrmann (edd.), Plato and the Poets (Leiden, 2011), 267-81.

${ }^{37}$ F. Nietzsche, The Birth of Tragedy from the Spirit of Music, $\$ 14$ in K. Ansell Pearson and D. Large (edd.), The Nietzsche Reader (Malden, MA and Oxford, [1872] 2006), 67. Compare Halliwell (n. 2), 98-117, whose discussion of 'the tragic worldview' seems more appropriate to the present passage than an emphasis on the 'heterogeneity' of imagination (at 94); cf. Liebert (n. 2 [2017]), 145-6.

38 So Moss (n. 2), 435.

39 S. Halliwell, Between Ecstasy and Truth: Interpretations of Greek Poetics from Homer to Longinus (Oxford, 2011), 179-207. 
at the start that he would rather not detail the harm of poetry out of fondness and reverence for Homer, but 'one must tell' the truth, twice using an impersonal imperative

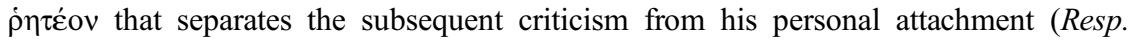
595b11, c5). Lest the sentiment, like the concession of wisdom at Resp. 605a3, seem ironic, the same emotional complex returns as the argument concludes. Socrates and Glaucon would gladly welcome mimetic poetry into a good political or psychological constitution because they are intimately aware of how enchanted they are by her

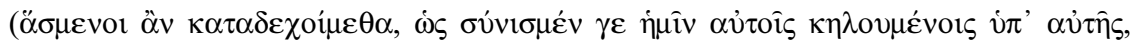
607c7-8), if only her benefit could be shown, whether in metre or by her lovers in prose $(607 \mathrm{~d} 4-\mathrm{e} 2) .{ }^{40}$ Yet, even without this defence, Socrates' erotic passion (है $\rho \omega \varsigma$, 607e5, 608a1) motivates him not to abandon mimetic poetry. He and Glaucon contrive, like lovers who must force themselves apart from a harmful beloved, to counteract their enchantment by singing a distillation of their argument as an 'incantation' while they

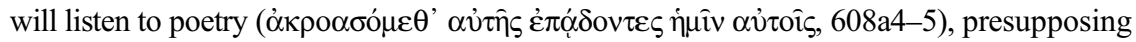
that they will continue to listen. ${ }^{41}$ This contrivance and, especially, the erotic imagery, connected like $\kappa \dot{\lambda} \lambda \eta \sigma \iota \varsigma$ at $601 \mathrm{~b} 1$ to beauty, reflect persistent but conflicted attraction. But perhaps by now this is unsurprising: poikilia always connoted danger amid admiration; Socrates has simply inverted the archaic proportions. The concept uniquely traces the contours of this ambivalent aesthetic response.

If this proposal is promising, it is terribly misleading to take poikilos at Resp. 604e605 a to connote what merely seems beautiful. This is false to Socrates' phenomenology. If it is not incoherent to say that what one loves merely seems but is not beautiful, it is disingenuous to say that it merely seems beautiful, as though it were insignificant, yet exerts so powerful a hold that one must remain on guard. This is not to deny that Socrates relates poikilia to a metaphysically, epistemically and ethically deficient notion of sensory appearance. Nor is to deny that Socrates encourages us to infer that what is poikilos is complex and seems beautiful, whereas what is beautiful is simple, for example by characterizing what makes music, virtue and gods beautiful ultimately in terms of the ontological nature of the form of beauty. ${ }^{42}$ But it is to suggest that this inference belongs to a rhetorical strategy that aligns poikilia with what seems (but may not be) beautiful for protreptic reasons, to undermine its analytic connection to beauty. Unless we recognize this strategy, we shall fail to appreciate the philosophical problem that Socrates' ambivalence illustrates. The problem is that one cannot neatly distinguish the fascinating yet harmful attraction marked by the concept of poikilia from the experience of beauty.

An initial difficulty is to identify the offending items. Suppose poikilia were opposed to beauty as 'complex' to 'simple'. If, however, its meaning and value are historically specific and constantly contested, as I have emphasized, then what it means to be 'complex' cannot be understood in purely descriptive or ontological terms, as though one could distinguish the right kind of music by counting the notes. It is precisely because there is no neutral evaluative ground on which to make his criticism, much less convince a partisan of the aesthetics of poikilia, that Socrates must strategically exploit the tensions internal to the concept.

${ }^{40}$ Mimetic poetry is personified as a hetaira, on which see Peponi (n. 30), 131-5.

${ }^{41}$ Cf. Phd. 77e3-9 for a partially parallel incantation against fear of death.

42 This contrast is best developed by Moss (n. 2), 427, 436. 
In so far as one such tension links poikilia with deception, a distinction might seem available, after all, along the lines of the contrast between seeming and being. Yet how is this contrast to be drawn? The case at hand is rather knottier than the one Socrates suggests for comparison. A straight stick in water 'merely seems' bent, because we rationally judge it to be straight (Resp. 602c11-d3). However, fascination in poikilia, like most encounters with beauty, is too absorbing for better judgement to hold sway, too awesomely compelling not to seem beautiful while in its grips. This is a psychological consideration, to be sure. But the underlying difficulty is conceptual. One cannot distinguish poikilia from beauty because both are constitutively modes of attractive appearance. Like his contemporaries, Plato typically conceives of beauty not in the early modern terms of an objective property or a subjective feeling but in the phenomenological terms of how something elicits in a human being a cluster of attitudes including erotic desire, psychosomatic pleasure, wonder and fascination. Such, however, is also the phenomenology of poikilia. ${ }^{43}$ If it is a conceptual truth that to be beautiful is in part to appear beautiful, then the contrast of appearance and reality, seeming and being, will be insufficient to demarcate what is beautiful from what is not. ${ }^{44}$

Of course, what seems beautiful may not be so. And it is significant in this regard that, whereas one can ask whether what seems beautiful really is so, there is no meaningful question whether what seems poikilos really is so. The metaphysical contrast does here gain traction. But the lesson, I would suggest, is that the apparent beauty of poikilia is, first, an appearance to the senses and, second, all there is to being poikilos. The structure of this appearance is not the presentation or disclosure of something else, as sensible beauty is for Plato (properly understood as) the disclosure of non-sensible being, the form of beauty. The lesson, or consequence, is not that this apparent beauty is illusory. Indeed, Socrates cannot quite claim that it is so. If beauty is the intentional object of erotic desire, which Socrates has for mimetic poetry, he should at some level find mimetic poetry beautiful. This may be at the level of non-rational psychology. But that should only reinforce the complexity of Socrates' attitude.

In arguing that, despite his cultural critique, Socrates keeps greater company with contemporary aesthetic attitudes than tends to be acknowledged, I mean to suggest that Plato preserves the tension within the concept of beauty remarked at the outset. On the one hand, if mimetic poetry is a dangerous pleasure, it becomes dissociated from beauty, as beauty relates closely to the good. Yet, on the other hand, the psychological-and conceptual-pressure to consider the object of this fascinating, indeed erotic, experience beautiful entails that the pursuit of beauty contains the possibility of peril. ${ }^{45}$ Beyond the difficulty of reconciling competing loves of philosophy and of poetry, Plato places under the sign of poikilia a more general problem in the ethical psychology of beauty: how should one respond to fascinating yet dangerous attractions?

${ }^{43}$ Cf. Menex. 234c5-235b2: funeral orators praise the war-dead 'so beautifully (ov̈ $\omega \varsigma \kappa \alpha \lambda \omega \varsigma$ ) that

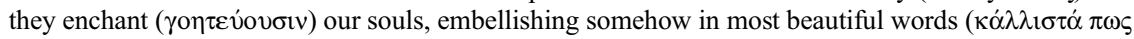

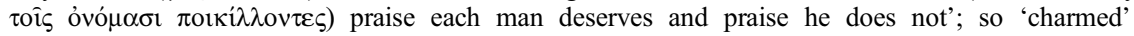

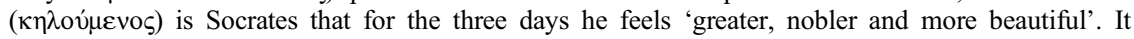
does not disturb the conceptual point that Socrates may be mocking orators, audiences and himself.

${ }^{44}$ Phdr. 250d3-e1 suggests the ontological basis of this point: Beauty is most self-disclosive

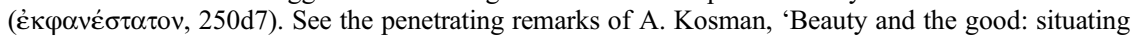
the kalon', CPh 105 (2010), 341-57.

${ }^{45}$ I discuss this point, and how beauty for Plato comes apart from the good, in the context of erotic desire in 'The guise of the beautiful: Symposium 204d ff.', Phronesis 65 (2019), 129-52. 


\section{SIGHTS AND SOUNDS, VISION AND WONDER}

This general problem subtends the discussion of cosmic poikilia from which we began. There, however, the problem takes shape from a metaphysical contrast between what is sensible as opposed to what is intelligible. The astronomical motions of heavenly bodies may point toward the intelligible, but risk absorbing one's attention further into the sensible world. This metaphysical contrast underwrites why for Plato poikilia cannot be analytic to beauty: because it is sensory, what is poikilos can be beautiful but not what it is to be beautiful. Before we return to the discussion of astronomy, it will help to observe how this particular target comes in the crosshairs of the argument at Resp. $475 \mathrm{~d}-480$ a that lovers of sights and sounds lack knowledge because the many beauties to which they are directed admit of being not-beautiful. ${ }^{46}$ Though understandably mined for its epistemological detail, the argument is framed by aesthetic and ethical considerations which have passed unremarked. ${ }^{47}$ This passage, I propose, works to displace the aesthetics of poikilia by subordinating a rather similar sensibility to a philosophical engagement with beauty.

The lovers of sights and sounds are characterized in two ways, before and after the argument. Each reflects a background concern with poikilia. The latter characterization focusses on ethical psychology. Because they do not attend to what remains always the same, lovers of sights and sounds 'wander' ( $\pi \lambda \alpha v \dot{\omega} \mu \varepsilon v o r)$ among sensible phenomena that vary every which way (Resp. 484b6-7). This is a consequence of the general principle that one's psychology becomes structured like what one admires. By 'wandering' Socrates means not only that their cognitive condition, belief ( $\delta$ ó $\xi \alpha)$, is unstable because it is structured toward changeable items but also that their characters are unstable; they themselves wander. This is presumably because their norms or standards (vó $\mu \mu \alpha)$, not merely their opinions, of beauty 'wander' ( $\pi \lambda \alpha v \eta \tau$ tóv, $479 \mathrm{~d} 8)$ or 'roll around' ( returns us to the matter of poikilia, is that, if one's ethical norms become so unmoored, one becomes vulnerable to thinking, like the democratic individual or the tyrant, that nothing is any more beautiful than ugly, good than bad or just than unjust (538d7e3). That is, if one attends toward what is sensible, not least its variety and multiplicity, rather than toward an ontological item as unitary and stable as the Beautiful Itself, then one is prone to that shameless pursuit of pleasure later characterized in terms of poikilia.

46 The controlling premise is that, whereas the Beautiful Itself is completely or purely ( $\tau \grave{o} \pi \alpha \nu \tau \varepsilon \lambda \hat{\omega} \varsigma$

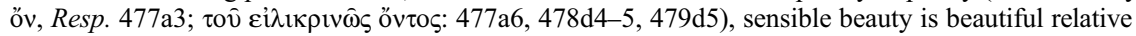
to some time, place, person, respect or comparison class; cf. Symp. 211a1-b5. The temporal condition is here forefront. The crucial move in the question-and-answer exchange is whether the many beautiful 'things' (objects or properties) will seem somehow ugly ( $\varphi \alpha v \eta \sigma \varepsilon \tau \alpha 1,479 \mathrm{a} 8$ ). Future tense is needed, because a lover is less likely to grant that a beloved now seems ugly than that beauty will fade. This is particularly so in the context of paiderasteia, which prefaces the argument: Socrates notes that lovers manage to admire any putative facial flaw of their beloveds $(474 \mathrm{~d} 2-475 \mathrm{a} 3)$.

47 The few scholars who connect the argument to the poikilia motif do so by relating the ontological deficiency of the sensible world to the multiplicity of poikilia: Petraki (n. 2); Liebert (n. 2 [2017]), 136 n. 45; Moss (n. 2), 426-8, 437, citing (at n. 35) Ti. 50d5: becoming as such is

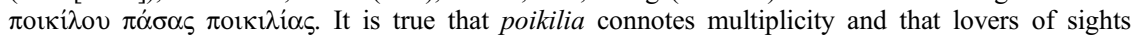
and sounds are comparable to, if not members of, audiences of mimetic poetry (cf. Resp. 601a5b2, 604e1-605a6). However, the concept does not appear in this passage and never refers in the Republic to precisely the ontological deficiency of the sensible world. Thanks to an anonymous reviewer for encouraging me to clarify this point.

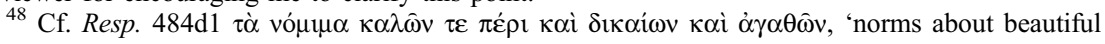
[noble, admirable], just and good things'. 
This is not to say that one of the lovers of sights and sounds' norms of beauty is poikilia. The text does not enter such detail. But the way in which these lovers are first characterized brings the aesthetics of poikilia more fully to the fore. Glaucon, we will recall, objects that, if a philosophos were simply a lover of all kinds of learning,

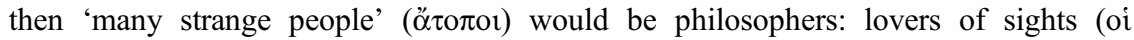

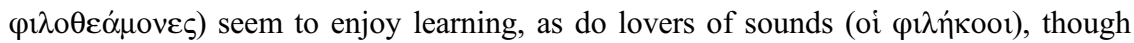
the latter folks would rather attend every Dionysian festival than a serious discussion

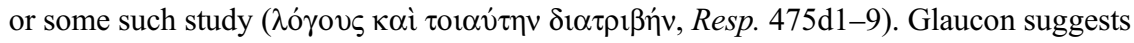
that common forms of intellectual culture, usually denoted by 'lover of sounds', ${ }^{49}$ including spectating and perhaps criticizing theatre, are just so much noise compared to philosophical discourse.

The theatrical context recalls the historical fact and foreshadows Socrates' criticism of poikilia as a cultural standard of both beautiful poetry and ethical character. So should the sensibility of the lovers of sights and sounds. They are positively attracted to beauty in so far as it 'appears to be many ... manifesting itself everywhere' ( $\pi \alpha \nu \tau \alpha \chi 0 \hat{v}$ $\varphi \alpha v \tau \alpha \zeta o ́ \mu \varepsilon v \alpha \pi \mathrm{o} \lambda \lambda \dot{\alpha}$ $\varphi \alpha i v \varepsilon \sigma \theta \alpha \mathrm{l}$, Resp. 476a6-7). Like those enraptured by the wondrous movement of Odysseus' golden brooch, they are attracted to beauty at the level of material composition: they 'embrace beautiful sounds, colours, shapes and everything

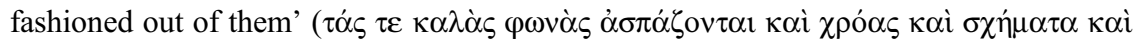

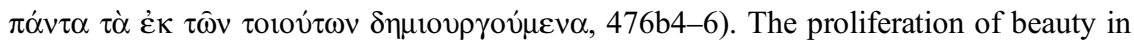
these phrases suggests that lovers of sights and sounds are not merely focussed on sensible beauty as opposed to some Platonic 'form' of beauty, as is most everybody. They are rather more stringently unwilling to grant that the variety of sensible beauty could be

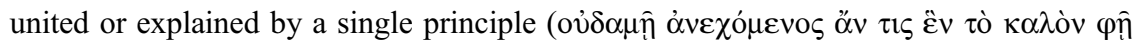
Eiv $\alpha 1,479 \mathrm{a} 5-6$ ). This orientation to beauty is remarkably congruous to the aesthetics of poikilia.

Plato must demarcate these figures from philosophers, and in so doing articulate the metaphysical limitation of the aesthetics of poikilia, because philosophy is characterized by a competing love of beauty. Seldom is the similarity duly emphasized, perhaps because readers assume that Plato opposes aesthetic and philosophical engagement as Glaucon does. ${ }^{50}$ Yet Plato has Socrates immediately remind Glaucon that these 'strange'

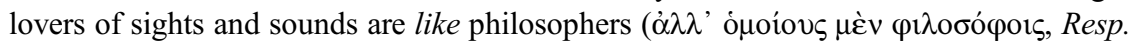
$475 \mathrm{e} 2-3$ ), just as he will have to remind Glaucon that the 'strange' ( $\dot{\alpha} \tau$ ó $\mathrm{o} \varsigma_{\text {) }}$ prisoners

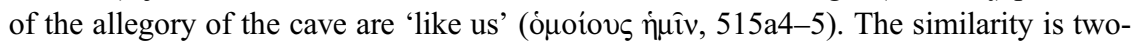
fold. Like philosophers, lovers of sights and sounds are committed to and enjoy learning, and they attempt to learn through an erotic pursuit of beauty. But the philosopher,

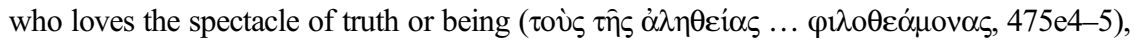
pursues what lovers of sights and sounds deny, namely all manifestations of beauty

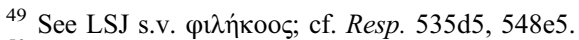

50 An impression furthered by labelling the lovers of sights and sounds derogatorily 'aesthetes'; e.g. D. Sedley, 'Philosophy, the forms, and the art of ruling', in G.R.F. Ferrari (ed.), The Cambridge Companion to Plato's Republic (Cambridge, 2007), 256-83, at 257-9. The obverse assumption, also common, is that the (sensible) kalon is here 'purely aesthetic' and non-ethical. Yet the kalon comes along with the just and the good, as elsewhere, and interest in learning at Athenian theatre extends beyond artistic technique to ethical and political matters, contra

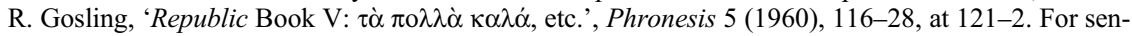
sitive attention to these points, see C. Meinwald, 'Who are the philotheamones and what are they

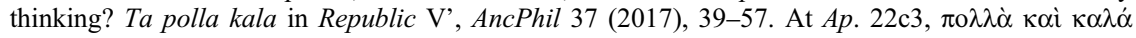
describes insights into human life and the divine; at Symp. 209e2, virtuous deeds. 
and pre-eminently the Beautiful Itself (476b6-c4). ${ }^{51}$ This creates a difference in ethical epistemology. The philosopher does not presume that one learns how to live well by attending plays to acquire, through sensation and cultural authority, putative exemplars of beauty or virtue as opposed to pursuing a systematic body of knowledge of their nature. And this creates, in turn, an aesthetic difference. The philosopher engages with beauty as grasped perceptually and intellectually, seeking in the many beauties a unifying principle by which to comprehend the variety in which lovers of sights and sounds revel, that they may discern sensible beauties as participants in the Beautiful Itself. The point to emphasize is that, if the philosopher shares some of the aesthetic habit as characterizes the aesthetics of poikilia, Plato must undermine this sensibility to make viable the pursuit of philosophy. Indeed, so far as ethical and epistemic progress relies on the vision of beauty, Plato competes on shared terrain.

This is terrain staked out by the study of astronomy discussed at Republic Book 7. Socrates extends the above argument but brings the ambivalent role of poikilia and its beauty centre stage. The heuristic value of admiring the heaven, we will recall, is qualified by Socrates' joke that to count contemporary astronomy among 'higher' studies, as Glaucon suggests, is to think one can learn something 'by looking with his head thrown back at decorations (poikilmata) on the ceiling' ('ُ $\pi$ oเкí $\lambda \mu \alpha \tau \alpha$ $\theta \varepsilon \dot{\omega} \mu \varepsilon v o \varsigma$, Resp. 529a10-b2). The term poikilmata captures the sensible nature and relative superficiality of observable astronomical motions, 'adorned', as it were, 'on the visible surface' of the heaven ('่v ó $\rho \alpha \tau \hat{\omega} \pi \varepsilon \pi$ oíkı $\lambda \tau \alpha 1,529 \mathrm{c} 8-9)$, as well as of their varying speeds, positions and orbits. These motions are thus not the 'true' astronomical motions, knowledge of which requires geometry. Yet this does not prevent the sort of mathematical astronomer whom Socrates advocates, for example Timaeus in the eponymous dialogue, from admiring how the 'wanderings' of the planets

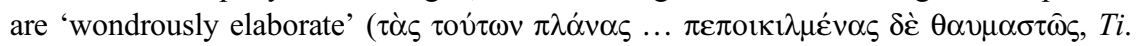
39d1-2) or, indeed, from reserving highest praise for those brightest, most beautiful,

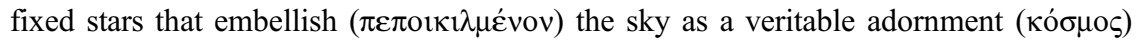
of the cosmos (Ti. 40a3-9).

Our initial puzzle was how Plato can have Socrates similarly praise the poikilia of the cosmos as beautiful while seeming to disparage poikilia as a harmful and rather not beautiful pleasure. The solution, we have seen, is that Plato grants that poikilia may be beautiful and its experience beneficial, but he exploits tensions within the concept to subvert its prominence as a cultural conception of beauty. Here in the context of astronomy, however, that pattern of admiration serves his philosophical purposes. By comparing astronomical motions to none other than Daedalus' plans for self-moving statues (Resp. 529e1), Socrates can appropriate a trope in archaic poetry of admiring the starry sky and prevailing associations of poikilia to beauty and divine expertise. ${ }^{52}$ Just as Daedalus' plans show the beautiful work of an intelligent craftsperson, the beauty and precision of the visible cosmos reveal it to be the most beautiful working-up of sensible material by the demiurge (530a6-7) and make it a useful model in the proper study of astronomy (529d8-9). To admire poikilia in this way is to restructure

\footnotetext{
${ }^{51}$ We are surely to recall the opening of the dialogue: Socrates went down to the Piraeus to observe the inaugural festival of Bendis and found the processions beautiful (Resp. 327a3-4). A.W. Nightingale, Spectacles of Truth in Classical Greek Philosophy: Theoria in its Cultural Context (Cambridge, 2004) analyses this appropriation of the practice of theōria.

52 See Grand-Clément (n. 2 [2011]), 548-52 for this archaic trope, echoed also at Phd. 110b5-d7.
} 
admiration toward the non-sensible nature of beauty. The point of displacing the aesthetics of poikilia is ultimately to put admiration of the beauty of poikilia in its proper place.

Why not conclude, perhaps more simply, that Plato distinguishes a beneficial from a harmful species of poikilia ${ }^{53}$ This strategy, though elegant, suppresses the essentially problematical character of the concept. Not only may only a rare philosophic few benefit from admiring astronomical motions but this benefit cannot eliminate-and Plato's re-conception of beauty merely mitigates - the risk of becoming more deeply absorbed in sensible beauty and its pleasures. This is a consequence of the fact that cosmic poikilia is intelligently arranged yet sensory, sitting precisely at the juncture of a deep ambivalence in Plato concerning the role and limits of vision in the philosophic life. Put generally, vision is a metonym for the foolishness of the senses but a metaphor for knowledge, and the vision of beauty often a necessary means to advance from the former toward the latter. ${ }^{54}$ The role of poikilia sharply focusses this broader ambivalence, ramifying on a cosmic scale the psychological ambivalence of Socrates toward the fascinating experience of mimetic poetry. Just as with the complexity of his phenomenology, so too we cannot in general distinguish beneficial from harmful species of poikilia or modes and objects of fascination. This distinction is either unavailable from within such an absorbing experience or inadequate to its combination of admiration and fear. We must hold both sides together to appreciate how ethical and epistemic progress for Plato must confront a problem of responding properly to fascinating yet dangerous attractions.

This conclusion contains an insight into the ethical psychology of beauty. Plato's treatment of the aesthetics of poikilia depends on the recognition that cultural conceptions of beauty shape in fundamental and non-rational ways the kind of life one admires and aspires to live. Balanced against the promise of beauty to manifest what a good life consists in and to move one to live accordingly is an acute worry that its experience can mislead: the pursuit of beauty is rife with anxiety and risk. Both sides of this coin reflect how beauty for Plato names both a cultural and philosophical problem and a potential solution: its wondrous - one might say fascinated—experience has the unique ability to disrupt how one ordinarily lives and to intimate more nourishing ways of living. But if one cannot tell this experience apart from the experience of poikilia, the dangers of the latter infiltrate the former; and if one must pursue beauty to live well, these dangers cannot be escaped and must be negotiated as one learns what it means to live well. A sense of beauty guides how we live. We follow its lead at great peril.

University of Hawai 'i at Mānoa

JONATHAN FINE

\footnotetext{
${ }^{53}$ As does the singularly sensitive treatment of Tulli (n. 3), e.g. at 235: 'Platone practica la Spaltung di matrice arcaica, divide. La poikilia negativa della produzione poetica non è certo la poikilia positiva.'

54 See N. Pappas, The Philosopher's New Clothes: The Theaetetus, the Academy, and Philosophy's Turn Against Fashion (New York, 2017), from whom I borrow the contrast of metonym and metaphor; and particularly in this connection, F. Gonzalez, 'The power and ambivalence of a beautiful image in Plato and the poets', in P. Destrée and R.G. Edmonds III (edd.), Plato and the Power of Images (Boston, 2017), 47-65.
} 